\title{
HASIL TANGKAPAN IKAN MADIDIHANG (Thunnus albacares) DI SAMUDERA HINDIA BERDASARKAN HASIL TANGKAPAN YANG DIDARATKAN DI PELABUHAN BENOA, BALI
}

Catch Product of Yellowfin Tuna (Thunnus albacares) catch landed in the Indian Ocean at Benoa Port, Bali

\author{
Krisliyana Mia Anggarini, Suradi Wijaya Saputra*), Abdul Ghofar, Bram Setyadji \\ Program Studi Manajemen Sumberdaya Perairan, Departemen Sumberdaya Akuatik \\ Fakultas Perikanan dan Ilmu Kelautan, Universitas Diponegoro \\ J1. Prof. Soedarto, SH, Tembalang, Semarang, Jawa Tengah - 50275, Telp/Fax. +6224 7474698 \\ Email : krisliyanamia@gmail.com
}

\begin{abstract}
ABSTRAK
Produksi ikan Madidihang yang cenderung menurun yang disebabkan oleh penangkapan yang berlebih dikhawatirkan dapat mengganggu kelestarian sumberdaya ikan Madidihang. Oleh sebab itu perlu adanya penelitian tentang hasil tangkapan ikan Madidihang. Hasil yang didapatkan dari penelitian diharapkan dapat memberi gambaran tentang kondisi ikan Madidihang di Samudera Hindia. Penelitian dilakukan pada bulan April-Mei 2016 di Pelabuhan Benoa. Penelitian ini bertujuan untuk mengetahui kondisi ikan madidihang melalui telaah panjang-bobot, faktor kondisi, ukuran pertama kali tertangkap, panjang asimtotik (L $\infty)$ ikan Madidihang di Samudera Hindia berdasarkan hasil tangkapan yang didaratkan di Pelabuhan Benoa, Bali. Metode yang digunakan yaitu metode survei. Pengolahan data menggunakan perangkat lunak microsoft excel. Hasil penelitian menunjukkan ukuran ikan Madidihang bulan April-Mei 2016 berkisar 70 - 178 dengan modus $112 \mathrm{cmFL}$. Persamaan hubungan panjang-bobot didapatkan $\mathrm{W}=0,00002 * \mathrm{FL}^{2,966}$ dengan pola pertumbuhan isometrik. Faktor kondisi yang didapatkan antara 1,64 - 2,44, dan ukuran ikan pertama kali tertangkap 133 cmFL. Panjang asimtotik $(\mathrm{L} \infty)=190,05 \mathrm{cmFL}$. Berdasarkan ukuran ikan yang tertangkap dimana $\mathrm{Lc}>1 / 2 \mathrm{~L} \infty$ dapat dinyatakan bahwa ukuran yang tertangkap telah layak tangkap.
\end{abstract}

Kata Kunci : Ikan madidihang; hubungan panjang-bobot, faktor kondisi, ukuran pertama kali tertangkap

\begin{abstract}
Yellowfin tuna production tends to decrease due to excess catching that is feared could interfere with the preservation of resources yellowfin tuna. Hence, it is necessary to do this research Catch Product of Yellowfin Tuna. Results obtained from the study are expected to give an idea of yellowfin condition in the Indian Ocean. This research was conducted in April-May 2016 at the Benoa Port. The aimed of this research was to determine condition of yellowfin tuna through the study of the length-weight relationship,condition factor, length at first capture, and asymptotic length $(L \infty)$ of yellowfin tuna in the Indian Ocean based on catches landed at the port of Benoa, Bali. This research used survey method. Data processing used the software of Microsoft Excel and FISAT II. The results have shown the size of the yellowfin tuna from April-May 2016 ranging from $70-178$ with $112 \mathrm{cmFL}$. The equation of length weights correlation was obtained $W=0.00002 * F L^{2,966}$ with isometric growth pattern. The condition factor obtained was between 1.64 to 2.44, and the size of the first caught fish is $133 \mathrm{cmFL}$. Asymptotic length $(L \infty)=190.05 \mathrm{cmFL}$. Based on the size of fish caught where Lc $>1 / 2 L_{\infty}$ can be stated that the size of which was caught had a decent catch.
\end{abstract}

Keywords: Yellowfin Tuna; length-weight relationship; condition factor, length at first capture

*) Penulis penanggungjawab

\section{PENDAHULUAN}

Wilayah Pengelolaan Perikanan 573 meliputi selatan Pulau Jawa, Bali, dan Nusa Tenggara merupakan bagian dari Samudera Hindia yang dikenal memiliki potensi sumberdaya perikanan pelagis besar yang tinggi. Total potensi sebanyak 491,7 ton per tahun yang terdiri dari ikan pelagis besar, ikan pelagis kecil, ikan demersal, udang penaeid, ikan karang konsumsi, lobster, cumi-cumi (Direktorat Sumberdaya Ikan, 2014). Ikan pelagis besar yang umumnya menjadi target tangkapan oleh nelayan terutama Tuna mata besar (Thunnus

\footnotetext{
${ }^{\circledR}$ Copyright by Management of Aquatic Resources (MAQUARES)
} 
obesus), Albakora (T. alalunga), Tuna sirip biru (T. maccoyii) dan Tuna sirip kuning (T. albacares). Ikan Madidihang merupakan salah satu jenis ikan tuna yang dominan tertangkap sepanjang tahun. Besarnya permintaan pasar akan meningkatkan eksploitasi terhadap perikanan tuna di Indonesia, sehingga dikhawatirkan dapat mengganggu kelestarian sumberdaya tuna. Permintaan pasar terhadap produksi ikan tuna yang terus meningkat telah mendorong upaya penangkapan yang semakin intensif, baik oleh perusahaan perikanan skala kecil maupun besar (Mardlijah dan Rahmat, 2012).

Eksploitasi sumberdaya ikan Madidihang di Samudera Hindia pada tahun 2011 - 2014 mengalami peningkatan jumlah tangkapan dari 329.184 ton di tahun 2011 menjadi 430.327 ton di tahun 2014. Kondisi tersebut menunjukkan bahwa jumlah tangkapan pada tahun 2014 sudah melebihi maksimum tangkapan lestari (MSY) yaitu lebih dari 404.000 - 439.000 ton. Berdasarkan hal tersebut pemanfaatan sumberdaya ikan Madidihang sudah lebih tangkap (overfishing) (IOTC, 2014). Beberapa tahun terakhir terjadi penurunan produksi ikan Madidihang yang didaratkan di Pelabuhan Benoa. Penurunan volume penangkapan ikan Madidihang mulai dari tahun 2011 senilai $3.006 .250 \mathrm{~kg}$, turun menjadi $1.383 .798 \mathrm{~kg}$ (tahun 2013).

Penelitian mengenai pendugaan ikan madidihang hasil tangkapan rawai tuna di Samudera Hindia penting dilakukan. Hasil yang didapatkan dari penelitian diharapkan dapat memberi gambaran tentang kondisi ikan madidihang di Samudera Hindia, sebagai bahan dalam pengelolaan sumberdaya ikan Madidihang.

\section{MATERI DAN METODE PENELITIAN}

\section{A. Waktu dan Tempat}

Penelitian ini dilaksanakan pada bulan April-Mei 2016 di Pelabuhan Benoa, Bali yang berkerja sama dengan kantor Loka Penelitian Perikanan Tuna (LP2T) Bali.

\section{B. Pengumpulan data}

Metode penelitian yang digunakan yaitu metode survei. Data yang dikumpulkan adalah data primer dan sekunder. Data primer dari pengukuran panjang cagak (FL) dilakukan menggunakan kaliper dengan ketelitian $0,5 \mathrm{~cm}$ dan berat ikan yang telah disiangi ditimbang dengan timbangan digital dengan ketelitian $0,1 \mathrm{~kg}$. Data sekunder diperoleh dari Loka Penelitian Perikanan Tuna tahun 2013 - 2014 ikan Madidihang yang merupakan hasil tangkapan rawai tuna yang beroperasi di Samudera Hindia.

\section{Pengambilan Sampel}

Pengambilan sampel ikan dilakukan selama 2 bulan yaitu bulan April-Mei 2016. Sampel ikan yang diambil selama penelitian berdasarkan ikan yang non ekspor. Jumlah ikan sampel yang didapat yaitu sebanyak 573 ekor ikan madidihang.

\section{Analisis Data}

\section{a) Struktur Ukuran}

Struktur ukuran ikan yang tertangkap dianalisis secara deskriptif dan disajikan dalam histogram berdasarkan data waktu penangkapan ikan (bulanan).

b) Hubungan panjang-bobot dan faktor kondisi

Hubungan panjang-bobot mengikuti persamaan sebagai berikut :

$$
\mathrm{W}=\mathrm{aFL}^{\mathrm{b}}
$$

Keterangan :

\begin{tabular}{|c|c|}
\hline $\mathrm{W}$ & $=$ berat tubuh setelah disiangi $(\mathrm{kg})$ \\
\hline FL & $=$ panjang cagak $(\mathrm{cm})$ \\
\hline & $\begin{array}{l}=\text { Intercept } \\
=\text { Slope }\end{array}$ \\
\hline
\end{tabular}

Dimana $b=3$, hubungan panjang dan berat adalah isometric, $b \neq 3$, hubungan panjang-bobot adalah allometrik.

Dalam perhitungan Kn (faktor kondisi) digunakan rumus Goddard dalam Effendi (2002).

$$
\mathrm{K}=10^{5} \mathrm{~W} / \mathrm{L}^{3}
$$

Dimana : W adalah bobot rata-rata ikan (g) sebenarnya dalam satu kelas dan L merupakan panjang rata-rata ikan $(\mathrm{cm})$ yang ada dikelas

\section{c) Ukuran pertama kali tertangkap}

Menurut Hartati et al. (2011), Jumlah individu dalam setiap kelas panjang ditransformasikan menjadi angka pecahan yang berjumlah 1. Angka pecahan tersebut diakumulasikan dari nilai tengah terkecil sampai terbesar, sehingga angka nilai tengah yang terbesar adalah 1 yang dinamakan lajur SL. Dari nilai SL dibuat lajur lainnya dengan nilai Ln (1/SL-1). Hubungan antara Ln (1/SL-1) sebagai (y) dengan nilai tengah sebagai (x) dengan menggunakan analisis regresi persamaan Ln $(1 / \mathrm{SL}-1)=\mathrm{S} 1-\mathrm{S} 2 *$ L. Nilai-nilai a dan b yang dihasilkan adalah nilai $\mathrm{S} 1$ dan $\mathrm{S} 2$, maka $\mathrm{Lc}=\mathrm{S} 1 / \mathrm{S} 2$. 
d) Panjang asimtotik

Perhitungan nilai panjang asimtotik menggunakan rumus Pauly (1984) dengan rumus:

$$
\mathrm{L} \infty=\mathrm{Lmaks} / 0,95
$$

\section{HASIL DAN PEMBAHASAN}

\section{A. Hasil}

\section{a) Struktur ukuran}

Ikan madidihang yang didaratkan di Pelabuhan Benoa, Bali selama bulan April-Mei 2016 sebanyak 573 ekor. Ukuran panjang yang tertangkap pada kisaran $70-180 \mathrm{cmFL}$, frekuensi terbesar terdapat pada kelas panjang 110 - $114 \mathrm{cmFL}$ sebanyak 82 ekor. Berdasarkan Gambar 1 terlihat adanya dua (2) puncak yakni pada panjang $112 \mathrm{cmFL}$ dan $157 \mathrm{cmFL}$.

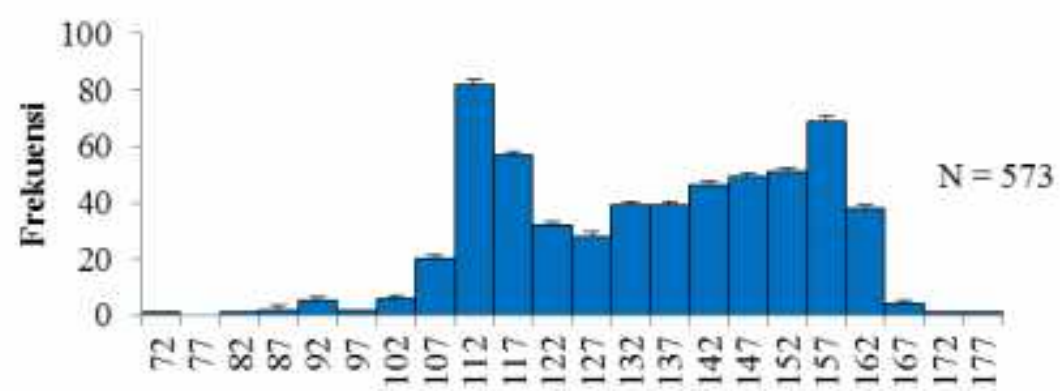

Panjang cmFL

Gambar 1. Struktur ukuran ikan madidihang yang didaratkan di pelabuhan Benoa bulan April-Mei 2016

\section{b) Hubungan panjang-bobot dan faktor kondisi}

Hubungan panjang-bobot ikan madidihang dari hasil tangkapan rawai tuna yang didaratkan di Pelabuhan Benoa yang mempunyai persamaan $\mathrm{W}=0,00002^{*} \mathrm{FL}^{2,966}$. Pola pertumbuhan ikan madidihang bersifat isometrik yaitu pertambahan panjang selaras dengan pertumbuhan bobot. Hal ini terlihat pada hasil uji $t$ dengan selang kepercayaan 95\%; $\mathrm{t}$ hitung $<\mathrm{t}$ tabel $(1,119<1,964) ; \mathrm{b}=2,966$. Hal ini dijelaskan pada kurva hubungan panjangbobot ikan Madidihang (Gambar 2).
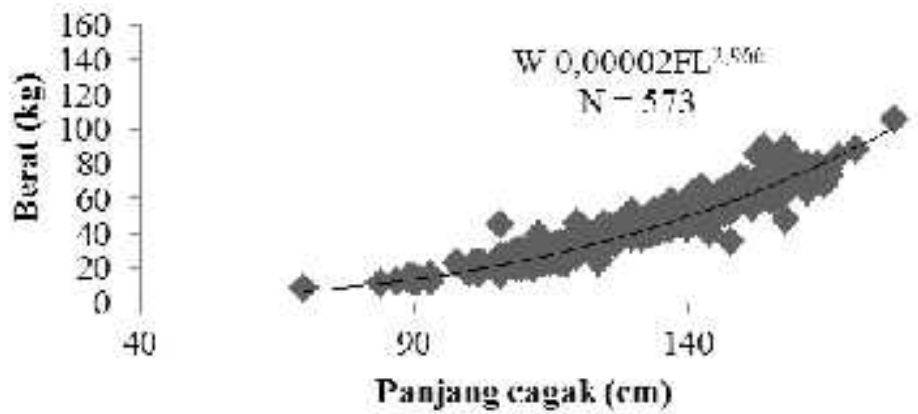

190

Gambar 2. Grafik hubungan panjang-bobot ikan madidihang yang didaratkan di Pelabuhan Benoa Bulan April - Mei 2016

Sebaran faktor kondisi ikan madidihang selama kegiatan penelitian disajikan pada (Gambar 3). Sebanyak 573 ekor diperoleh nilai $\mathrm{K}$ antara 1,71 - 1,99 dengan rata-rata nilai faktor kondisi adalah 1,83.

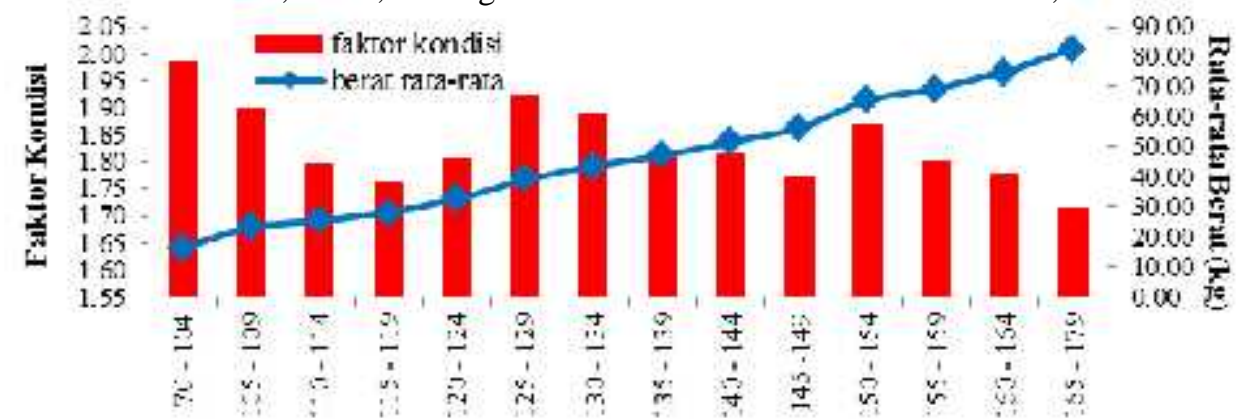

Kusaran Panjang cmrL

Gambar 3. Faktor kondisi ikan madidihang yang didaratkan di Pelabuhan Benoa Bulan April - Mei 2016

${ }^{\circledR}$ Copyright by Management of Aquatic Resources (MAQUARES) 
c) Ukuran pertama kali tertangkap

Hasil perhitungan ukuran pertama kali tertangkap ikan Madidihang diperoleh ukuran sebesar $133 \mathrm{cmFL}$. Ukuran terkecil ikan madidihang yang tertangkap pada penelitian ini panjang $70 \mathrm{cmFL}$ dan ukuran terpanjang yaitu $178 \mathrm{cmFL}$. (Gambar 4).

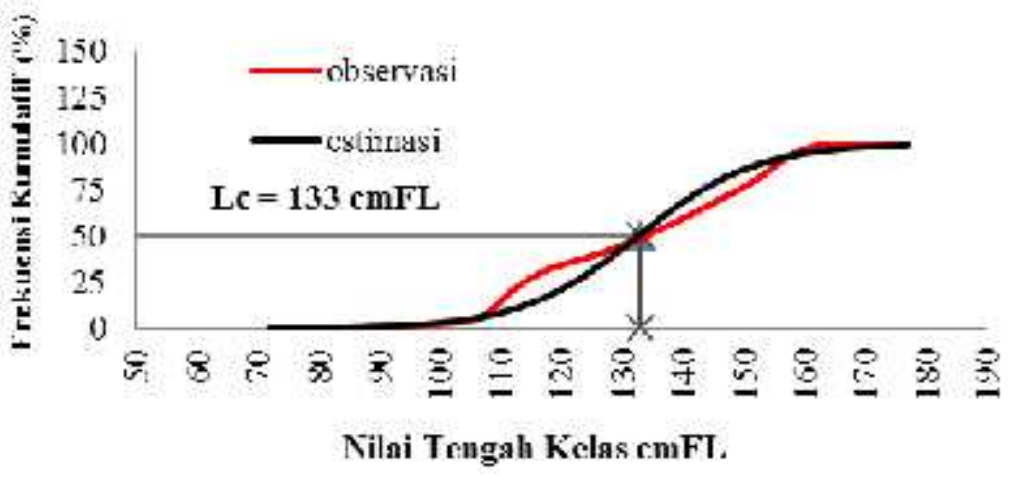

Gambar 4. Grafik Lc Ikan Madidihang yang Didaratkan di Pelabuahan Benoa Bali bulan April - Mei 2016

\section{B. Pembahasan}

\section{a) Struktur ukuran}

Hasil penelitian menunjukkan bahwa jumlah frekuensi panjang ikan tuna madidihang berkisar anta 70 $178 \mathrm{cmFL}$ dengan rata-rata 134,39 cmFL. Jumlah terbesar terdapat pada kelas 110 - 114 yaitu dengan panjang cagak rata-rata 112,25 cmFL sebanyak 82 ekor. Andamari et al., (2012) menjelaskan bahwa kisaran panjang ikan madidihang yang didaratkan di Pelabuhan Benoa antara 112 - $160 \mathrm{cmFL}$ dengan rata-rata 141,5 cmFL artinya ukuran yang tertangkap pada tahun 2011 lebih kecil namun ukuran yang kurang dari 100 tidak tertangkap. Hal ini berarti pada tahun 2016 banyak ikan yang ukurannya $<100 \mathrm{cmFL}$ tertangkap oleh rawai tuna sekitar 50 ekor.

Salah satu komponen penting dalam mengolah data tangkapan adalah data frekuensi panjang (Herrera, \& Pierre, 2011 dalam Setyadji, 2015). Terlihat bahwa grafik frekuensi panjang ikan madidihang tidak menunjukkan suatu distribusi normal. Hal ini diduga terdapat dua kelompok umur yang mendominasi dalam hasil tangkapan ikan madidihang selama bulan April-Mei 2016 ini. Hal ini diduga bahwa stok ikan Madidihang di daerah penangkapan terdiri dari dua kelompok stok.

\section{b) Hubungan panjang berat dan faktor kondisi}

Nilai b dari hubungan panjang-bobot ikan madidihang adalah 2,966, nilai tersebut mendekati 3 . Pola pertumbuhan bersifat isometric yaitu $b=3$. Hal ini terlihat pada hasil uji $t$ dengan selang kepercayaan $95 \%$; $t$ hitung < t tabel $(1,119<1,964) ; b=2,966$. Menurut Effendie (2002), jika nilai $b=3$ maka pertumbuhan bersifat isometrik. Hasil yang sama didapatkan menurut penelitian di perairan India (Rohit et al., 2012; Kar et al., 2012). Hasil yang berbeda dengan penelitian di perairan Atlantik dan Samudera Pasifik bagian timur (Zhu, et al., 2010). Hasil penelitian di Samudera Hindia (Zhu, et al., 2010; Andamari et al., 2012; Miazwir, 2012) bersifat allometrik negatif $(b<3)$ yaitu pertumbuhan panjang lebih cepat daripada pertumbuhan beratnya, sedangkan hasil lain dari (Muhammad, N. \& A. Barata, 2012) di samudera hindia bersifat allometrik positif (b>3). Pada beberapa penelitian terjadi perbedaan yang dapat disebabkan oleh ukuran masing-masing ikan. Menurut Nurdin et al. (2012), perbedaan pola pertumbuhan dapat disebabkan karena ukuran ikan hasil tangkapan yang berbeda. Ikan yang hidup pada permukaan perairan sangat dipengaruhi oleh faktor lingkungan diantaranya ukuran dan jenis makanan, suhu, oksigen, dan umur ikan.

Nilai faktor kondisi ikan madidihang yang didapatkan di penelitian antara 1,71 - 1,99 yang berarti ikan memiliki badan kurang pipih. Hal ini sesuai dengan pendapat Effendie (1997) bahwa nilai K berkisar antara 1 3 yaitu badan ikan kurang pipih. Hal yang sama pada penelitian (Wijaya, 2012; Miazwir, 2012) di Samudera Hindia bahwa nilai faktor kondisi antara 1 - 3 yang berarti badan kurang pipih. Berdasarkan Effendie (1997), nilai yang tinggi menunjukkan bahwa ikan yang tertangkap gemuk. Hal ini kemungkinan disebabkan karena kondisi lingkungan yang baik, adanya makanan atau tersedianya makanan dan hampir semua di kelas panjang memiliki nilai faktor kondisi yang tidak jauh berbeda.

\section{c) Ukuran pertama kali tertangkap}

Hasil yang didapatkan dari perhitungan data panjang telah diperoleh ukuran pertama kali tertangkap (length at first capture/ Lc) ikan madidihang sebesar $133 \mathrm{cmFL}$. Ikan hasil tangkapannya didominasi oleh ukuran panjang 133 - 178 cmFL sebanyak 58,81\%. Menurut FAO (2010) dalam Muhammad dan Barata (2012), ukuran ikan madidihang yang matang gonad tertangkap di Samudera Hindia berada pada kisaran panjang $100-110 \mathrm{cmFL}$ atau ikan berumur 2,5 - 3 tahun. Hal ini dapat diasumsikan bahwa ikan madidihang

$$
\text { () Copyright by Management of Aquatic Resources (MAQUARES) }
$$


yang tertangkap oleh kapal rawai tuna yang belum matang gonad sebanyak $1,92 \%$, sedangkan ikan yang siap melakukan pemijahan jumlahnya $6,98 \%$, sedangkan sisanya sebanyak $91,1 \%$ sudah melakukan pemijahan. Hal ini bererti bahwa lebih dari 50\% ikan Madidihang telah memijah.

\section{KESIMPULAN}

Struktur ukuran dan sebaran ikan madidihang yang tertangkap oleh armada rawai tuna pada bulan AprilMei 2016 yaitu antara 70 - $178 \mathrm{cmFL}$. Berdasarkan analisis hubungan panjang berat didapatkan bahwa pola pertumbuhan ikan madidihang adalah isometrik dan faktor kondisi ikan madidihang tergolong tidak pipih, serta ukuran ikan pertama kali tertangkap yaitu $133 \mathrm{cmFL}, \mathrm{L} \infty=190,05 \mathrm{cmFL}$. Nilai Lc $>$ Lm hal ini menunjukkan keberlanjutan stok dapat terus berlanjut.

\section{UCAPAN TERIMAKASIH}

Ucapan terima kasih ditujukan kepada Drs. Ign. Boedi Hendrarto, M.Sc, P.hD; Ir. Anhar Solichin, M.Si; Prof. Dr. Ir. Supriharyono, M.S; Dr. Ir. Pudji W. Purnomo, M.S; Churun Ain, S.Pi, M.Si, yang telah memberikan masukan serta arahan kepada penulis. Kepada Budi Nugraha, S.Pi, M.Si; Bram Setyadji, S.Kel, M.Si; dan pihak LPPT Benoa Bali yang telah memberikan ijin, bimbingan selama penulis di LPPT Benoa, Bali.

\section{DAFTAR PUSTAKA}

Andamari, R., J. H. Hutapea, dan B. I. Prisantoso. 2012. Aspek Reproduksi Ikan Tuna Sirip Kuning (Thunnus albacares). Jurnal Ilmu dan Teknologi Kelautan Tropis., 4(1): 89 - 96.

Direktorat Sumberdaya Ikan. 2014. Rencana Strategis Dirjen Perikanan Tangkap 2010 - 2014, 134 hlm.

Effendie. 1997. Biologi Perikanan. Yayasan Pustaka Nusantara, Yogyakarta, 163 hlm.

2002. Biologi Perikanan. Yayasan Pustaka Nusantara, Yogyakarta, $163 \mathrm{hlm}$.

Hartati, T., Suwarsono, dan M. Taufik. 2011. Komposisi Ukuran, Tingkat Kematangan Gonad, dan Makanan Ikan Banyar di Perairan Kendari. Balai Penelitian Perikanan Laut, Jakarta, 209 - 226.

IOTC (Indian Ocean Tuna Commission). 2014. Executive Summary Yellowfin Tuna. 3 hlm.

Kar, A. B., L. Ramalingam, K. Govindaraj, and G. V. A. Prasad. 2012. Study of The Growth and Population Parameters of Yellowfin Tuna (Thunnus albacares) in the Andaman and Nicobar Waters Based on the Length Frequency Data. IOTC-2012-WPPTT14-30, 16pp.

Mardlijah, S. dan E. Rahmat. 2012. Penangkapan Juvenil Ikan Madidihang (Thunnus albacares Bonnatere 1788) di Perairan Teluk Tomini. Jurnal Bawal., 4(3):169 - 176.

Miazwir. 2012. Analisi Aspek Biologi Reproduksi Ikan Tuna Sirip Kuning (Thunnus albacares) yang Tertangkap di Samudera Hindia. [Tesis]. Program Magister Ilmu Kelautan, Universitas Indonesia, Depok, $68 \mathrm{hlm}$.

Muhammad, N., dan A. Barata. 2012. Struktur Ukuran Ikan Madidihang (Thunnus albacares) yang Tertangkap Pancing Ulur di Sekitar Rumpon Samudera Hindia Selatan Bali dan Lombok. Jurnal Bawal., 4(3):161 $-167$.

Nurdin, E., A. A. Taurusman, dan R. Yusfiandani. 2012. Struktur Ukuran, Hubungan Panjang Berat, dan Faktor Kondisi Ikan Tuna di Perairan Prigi, Jatim. Jurnal Bawal., 4(2):67 - 73.

Pauly, D. 1984. Fish Population Dynamic in Tropical Waters: A manual for Use With Programmable Calculators. ICLARM, Manila.

Rohit, P., G. S. Rao, and K. Rammohan. 2012. Age, Growth and Population Structure of the Yellowfin tuna Thunnus albacares (Bonnaterre, 1788) Exploited Along The East Coast of India. Indian J. Fish., 59(1):1 - 6 .

Setyadji, B. 2015. Dinamika Populasi Ikan Pedang (Xiphias gladius L) di Perairan Samudera Hindia. [Tesis]. Program Pascasarjana, Universitas Udayana, Denpasar, 68 hlm. 
Wijaya, Handi. 2012. Hasil Tangkapan Madidihang (Thunnus albacares) dengan Alat Tangkap Pancing Tonda dan Pengelolaannya di Pelabuhan Perikanan Nusantara Pelabuhan Ratu Sukabumi. [Tesis]. Program Magister Ilmu Kelautan, Universitas Indonesia, Depok, 138 hlm.

Zhu, G., L. Xu, Y. Zhou, L. Song, and X. Dai. 2010. Length Weight Relationship for Bigeye tuna (Thunnus obesus), Yellowfin tuna (Thunnus albacares) and Albacora (Thunnus alalunga) (Perciformes: Scrombinae) in the Atlantic, Indian, and East Pasific Oceans. College of Marine Science. Shanghai Ocean University, Cina., 65(2):717 - 724. 